\title{
Antispermatogenic effects of 5-aminoindazole in rats
}

\author{
T. J. Lobl and S. E. Porteus \\ Fertility Research, The Upjohn Company, Kalamazoo, Michigan 49001, U.S.A.
}

Over the years a variety of antispermatogenic compounds have been found and some of their properties characterized (Jackson, 1966; Silvestrini et al., 1975; Patanelli, 1975). During the course of screening chemicals that are potentially active in the male reproductive system, 5-aminoindazole was discovered and this report presents some of the data that characterize its antispermatogenic and antifertility properties.

Initial experiments with mature and immature rats(Sprague-Dawley) demonstrated that the drug (Aldrich Chemical Co.) was effective in reducing testicular weights and disrupting spermatogenesis without significantly affecting seminal vesicle or ventral prostate weights. The compound was found to be active orally (in $1 \%$ gum tragacanth) or subcutaneously (in $0.25 \%$ methycellulose) when doses of $\geqslant 200 \mathrm{mg} / \mathrm{kg}$ were given. (The compound is also orally active in mice and hamsters but is less potent and more toxic.) When mature rats were given one s.c. dose of $200 \mathrm{mg} 5$-aminoindazole/kg, a focal seminiferous tubular exfoliation of immature germ cells and giant multinucleated cell formations were observed. Multiple doses produced a similar but more generalized effect on the testicular parenchyma.

In the present experiments administration of 4 oral doses of $200 \mathrm{mg} / \mathrm{kg} /$ week for 2 weeks was sufficient to cause a rapid decline in testicular weight and to disrupt spermatogenesis sufficiently to cause sterility. As shown in Table 1, there was a rapid decline in relative testicular weights following drug treatment. Although the weight of the gonad subsequently increased after the nadir on Day 10 , the weight loss was never fully regained.

Table 1. Effects (weight, as \% of control weight) of oral treatment with $200 \mathrm{mg}$ 5-aminoindazole hydrochloride/kg (4 doses/week for 2 weeks) on male rats

\begin{tabular}{ccccccc}
\hline Exp. & $\begin{array}{c}\text { No. of } \\
\text { rats }\end{array}$ & $\begin{array}{c}\text { Day } \\
\text { killed }\end{array}$ & $\begin{array}{c}\text { Final } \\
\text { body } \\
\text { wt }\end{array}$ & $\begin{array}{c}\text { Absolute } \\
\text { testis } \\
\text { wt }\end{array}$ & $\begin{array}{c}\text { Seminal } \\
\text { vesicle } \\
\text { wt }\end{array}$ & $\begin{array}{c}\text { Ventral } \\
\text { prostate } \\
\text { wt }\end{array}$ \\
\hline 1 & 4 & 10 & $66^{* * *}$ & $48^{* * *}$ & 78 & $45^{* *}$ \\
2 & 5 & 21 & 89 & $56^{* *}$ & 96 & 106 \\
3 & 3 & 62 & 101 & $61^{* *}$ & 84 & 106 \\
4 & 4 & 132 & 95 & $62^{*}$ & 114 & 99 \\
\hline
\end{tabular}

${ }^{*} P<0.05 ;{ }^{* *} P<0.01 ;{ }^{* * *} P<0.001$ (Dunnet many-to-one $t$-test using pooled variance).

Microscopic examination of testicular cross-sections of rats killed on Day 132 revealed that about $25 \%$ of the seminiferous tubules contained only Sertoli cells and showed no signs of spermatogenic activity despite the long recovery time. Prolonged treatment with 5-aminoindazole might, therefore, lead to permanent sterility. No changes in the interstitial cells were observed in any of the treated animals. Very few spermatozoa or immature germ cells were present in the epididymides by Day 21. Spermatozoa extracted from the cauda epididymidis into saline on Day 10 were mainly decapitate or immotile, while intact spermatozoa had tails bent from 90 to $180^{\circ}$ around a cytoplasmic droplet.

In an experiment designed to determine if 5-aminoindazole had a direct effect on spermatozoa, the caudal portions of rat epididymides were sliced into Medium 199. The exuded spermatozoa were incubated for $3.5 \mathrm{~h}$ at $25^{\circ} \mathrm{C}$ in Medium 199 containing 1-100 $\mu \mathrm{g}$ 5-aminoindazole (hydrochloride salt)/ml and were frequently monitored for morphological alterations and motility changes relative to the controls. There were no apparent effects on sperm motility or morphology, suggesting an indirect effect of the drug on sperm morphology.

The reduction in body weight on Day 10 (Table 1) might have been due to a toxic side effect. The 
temporary, but significant, reduction in ventral prostate weight led to an experiment of $2 \times 2$ factorial design to see whether s.c. administration of testosterone propionate (dissolved in $5 \%$ benzyl alcohol, diluted with cottonseed oil and given at a dose of $500 \mu \mathrm{g} / 250 \mathrm{~g}$ rat/day) with the drug would ameliorate the damage to the germinal epithelium. The testicular damage was just as severe and the prostatic weights were still reduced. Since spermatogenesis can be supported by testosterone alone in a postpubertal rat (Sanborn, Elkington, Steinberger, Steinberger \& Meistrich, 1976), it seems unlikely that an antigonadotrophic mechanism was operating.

Table 2. Effect (no. of females with implantations (average in parentheses)/no. in group) of 5-aminoindazole hydrochloride on the fertility of male rats assessed by mating at various times from Week 4 (i.e. from Day 21 of experiment)

\begin{tabular}{lcccccccccc}
\hline & \multicolumn{10}{c}{ Week } \\
\cline { 2 - 10 } & 4 & 5 & 6 & 7 & 8 & 10 & 11 & 12 & 13 & 14 \\
\hline Control & $3 / 6$ & $4 / 6$ & $5 / 6$ & $6 / 6$ & $6 / 6$ & $3 / 3$ & $3 / 3$ & $3 / 3$ & $3 / 3$ & $3 / 3$ \\
& $(9)$ & $(10)$ & $(8)$ & $(9)$ & $(12)$ & $(12)$ & $(13)$ & $(13)$ & $(12)$ & $(8)$ \\
Treated & $0 / 7$ & $0 / 7$ & $0 / 7$ & $0 / 7$ & $0 / 7$ & $0 / 4$ & $0 / 4$ & $1 / 4$ & $2 / 4$ & $3 / 4$ \\
& $(0)$ & $(0)$ & $(0)$ & $(0)$ & $(0)$ & $(0)$ & $(0)$ & $(3)$ & $(8)$ & $(4)$ \\
\hline
\end{tabular}

Fertility tests were conducted by serially mating the control and treated male rats with prooestrous females. Implantations were counted on Day 14 after finding spermatozoa in the vagina or a seminal plug. The results are shown in Table 2 . Infertility was already apparent by Week 4 . Spermatogenesis must have resumed soon after cessation of drug administration, because all 3 animals killed on Day 62 had large numbers of spermatozoa in the caput epididymidis, despite the severe depletion of spermatocytes and spermatids found histologically at Days 10 and 21 (Table 1). This time interval is approximately correct for the development of spermatogonia to spermatozoa (Jackson, 1966). The uneven drug effect on the testis tubules, however, prevents the establishment of germ cell dormancy as a second action of 5-aminoindazole in addition to the observed exfoliation of immature germ cells. Fertility began to return by Week 12 and by Week 14, 3 of 4 animals were fertile. Microscopic examination of the testes of the fourth animal showed that more than $95 \%$ of the seminiferous tubules contained Sertoli cells only or were spermatogenically inactive.

We conclude from these experiments that 5 -aminoindazole is an active antispermatogenic compound which appears to have secondary effects on epididymal spermatozoa. It induces the exfoliation of immature germ cells, a characteristic of other antispermatogenic agents (DeMartino et al., 1975; Lobl \& Porteus, 1976) and produces a long-lasting infertility. The determination of the exact mechanism of action of the drug must await further studies.

\section{References}

DeMartino, C., Stefanini, M., Agrestini, A., Cocchia, D., Morelli, M. \& Barcellona, P.S. (1975) Antispermatogenic activity of 1-p-chlorobenzyl1H-indazol-3-carboxylic acid (AF 1312/TS) in rats. Exp. Molec. Path. 23, 321-356.

JaCkson, H. (1966) Antifertility Compounds in the Male and Female. Charles $\mathrm{C}$. Thomas, springfield.

LOBL, T.J. \& PORTEUs, S.E. (1976) Characterization of the antispermatogenic effects of 1-(2,4-dichlorobenzyl)-indazole-3-carboxylic acid in the rat. Proc. 9th A. Meeting, Soc. Study of Reproduction, Philadelphia, Abstr. 109, p. 70.

Patanelei, D.J. (1975) Suppression of fertility in the male. In Handbook of Endocrinology, Vol. V, Sect. 7, pp. 245-258. Eds D. W. Hamilton \& R. O. Greep. Am. Physiol. Soc., Washington, D.C.

Sanborn, B.M., Elkington, J.S.H., Steinberger, A., Steinberger, E. \& Meistrich, M.L. (1976) Androphilic proteins in the testis (discussion following the paper). In Regulatory Mechanisms of Male Reproductive Physiology, pp. 45-62. Eds C. H. Spilman, T. J. Lobl \& K. T. Kirton. Elsevier, New York.

Silvestrini, B., Burberi, S., Catanese, B., Cioli, V., Couston, F., Lisciann, R. \& Barcellona, P. S. (1975) Antispermatogenic activity of 1-p-chlorobenzyl-1H-indazol-3-carboxylic acid (AF 1312/TS) in rats. Exp. Molec. Path. 23, 288-307. 